\title{
Benefits of International Education Cooperation: Perspectives from China-Cameroon Education Cooperation
}

\author{
Mvuh Zouliatou $^{1 *} \quad$ Liu Hongwu ${ }^{2 *}$ \\ Institute of African Studies, Zhejiang Normal University \\ PO box 321000, Jinhua City, China
}

\begin{abstract}
This study analyses the benefits of international education cooperation with spotlight on the educational cooperation between China and Cameroon. The paper discussed the theoretical framework of the benefits of international education cooperation, it explores the nature and structure of international education cooperation with focus on the China-Cameroon cooperation and concludes with the benefits to both partners in this type of cooperation.
\end{abstract}

Keywords: International Education, Cooperation, China, Cameroon

DOI: $10.7176 / \mathrm{JEP} / 10-29-03$

Publication date:October $31^{\text {st }} 2019$

\section{Introduction}

Education has been seen as a vehicle for nations to address the basic requirements of human and social development. This is the reason why many African countries and Cameroon in particular have been making efforts to enhance education quality in their respective locations. In the process of this, Cameroon established strong links with China which is today a major partner in the education sector. China-Cameroon education cooperation goes back to the 1980s after the two countries established their diplomatic ties in 1971. Though the said cooperation is still very young, however, the two partners have succeeded in achieving a lot in this area. The China-Cameroon education cooperation relies on the policy of mutual respect, mutual learning, mutual trust and common development, which is believed to be helpful in strengthening the goal of education exchange as well as drawing and sharing development experiences (China, 2006).

Like with many other African nations, China-Cameroon education cooperation adopted a deliberate shift from the unilateral approach at the onset to a diversified form after the establishment of the Forum on China-Africa Cooperation (FOCAC) in 2000 (Baoping, 2006; Ping, 2013; Niu, 2010; He, 2007; Lou, 2014; Li Anshan et al.). In other words, China shifted from cooperating through the governmental path only to include diversified institutions and private stakeholders. Thus, the educational cooperation between China and Cameroon has involved scientific research projects and inter-university collaborations; human resource development programs such as scholarship provision and personnel training; provisions of primary and secondary schools building and learning and teaching materials (Mvuh, 2017; Nordtveit, 2011; Niu, 2010).

This form of cooperation has culminated in diverse benefits both for China and Cameroon. However, before analyzing the benefits of the China-Cameroon education cooperation, it is important to first review theoretical conception and benefits of international education cooperation.

\section{Theoretical Basis of International Education Cooperation}

International cooperation in education encompasses international initiatives targeted at achieving learning, intellectual exchange and education in general, and it is implemented in the formal academic relations through bilateral and scientific agreements among countries (McGrath, Simon; Gu, 2015). International education cooperation is recognized to bring together people from different cultural backgrounds, with different styles and outlooks of teaching and learning in addition to the sharing and transfer of knowledge (Wessala, 2011; Wiseman, 2018). Tate Nicholas (2013), argued that international cooperation in education promotes international understanding, global awareness and international mindedness; it helps people to be engaged in global citizenship; improve respect for differences and encourage tolerance in addition to commitment to peace (Cambridge, James; Thompson, 2004; Tate, 2013).

International education cooperation is seen by some (Cambridge, James; Thompson, 2004; Hayden, Mary; McIntosh, 2018b; McCollow, 1989a) as presenting many advantages and benefits that can be observed in three gradual levels:

- Individual level

- Institutional level

- Governmental level

First, the individual benefits generally cited are linked to students and teachers who live or have lived some international experiences. Therefore, international education cooperation provides students the opportunity to develop intercultural skills through the interactions with domestic or other international students and teachers 
coming from different countries. It helps to cultivate good habits and enhance relationships and behavior. For instance, through communication and exchanges between students from different cultural backgrounds, they are able to cultivate positive attitudes regarding diversity in society, reduce prejudices, respect the rights of others, improve engagement in learning and are challenged to be more creative (British Council, 2014). Furthermore, it is argued the intercultural skills gained by students during their international experiences, notably the communication and interpersonal skills, foreign language acquisition, community building, self-directed learning, are transferrable skills and have value in a broad range of jobs and contribute to social cohesion (Hayden, Mary; McIntosh, 2018a). Hence, international cooperation in education can be an efficient strategy for improving individual's career prospects, particularly if the individual was unable to obtain at home the required skills and knowledge. Fostering intercultural skills and creating international networks can therefore prepare students both international and domestic to work and live in a globalized world. In addition to the student's individual benefits in international education cooperation, Lucker \& al. (1976) estimated that this kind of cooperation offers opportunity to student to produce higher level of academic achievements across cooperative learning in culturally mixed groups (Lucker, G. W., Rosenfield, D., Sikes, J., \& Aronson, 1976). It is also increase cross-ethnic friendships in which moral, intellectual and development values can be shared (Cambridge, James; Thompson, 2004; Wiegel, R. H., Wiser, P. L. , \& Cook, 1975).

At the institutional level, international education cooperation enriches the learning environments with international students and teachers which enhances the improvement of international understanding within campuses (McCollow, 1989b). The presence of these international teachers and students on campuses is a major factor of internationalization of higher education, as they enormously contribute to activities aiming at enhancing the competitiveness and efficiency of higher education institutions in the global marketplace. Through the internationalization of the institution, students and teaching staff can benefit from scholarships and research opportunities that could enhance job mobility within the university Knight (2000). Moreover, the increasing number of international students in internationalized universities are additional funding opportunities.

Thirdly, the benefit of international education cooperation to the government is generally associated with economic matters and opportunities for countries to gain strong reputation internationally. In this sense, Lee, Therriault \& Linderholm, (2012) argued that, international education cooperation increases employability and creative thinking through the development of transferrable skills, that can enable the participant in international experiences to economically contribute to his or her country development. In long term, students who have international experiences can add to domestic pool of highly-skilled and experienced workers thereby reinforcing the knowledge economy. It is argued that students who return home after their studies abroad can become ambassadors for the industry of the country and higher education institutions in which they studied and can therefore contribute to trade relations and international cooperation. Moreover, international students and international staff across international education cooperation bring additional revenue to the host county through their living expenses. According to Cambridge, James; Thompson, Jeff (2004), international cooperation in education have evident relationship with the economy and cultural globalization with respect to the increasing needs for education qualifications to be transferable amongst the education system and schools; and also regarding the expansion of global quality standards across quality assurance procedures.

With regard to the above arguments, Bennett developed a model of intercultural experience that articulates potential benefits related to international education cooperation in term of skills, behavior, attitude and knowledge obtained through intercultural interactions. This model has been very useful because, in addition to describing the benefits of international cooperation, it also provides explanation of the mechanism through which the international competences are developed. For instance, Bennett's model suggests "it is the experience of cultural difference that is responsible for the development of intercultural competences".

Bennett's model presents six stages of development partitioned into two different groups. Each stage pictures a different manner to be engaged with cultural difference. The initial group of three stages mark the "ethnocentrism" and provide information on how people view difference as immutable and threatening. The second and final stage is labeled "ethno-relative" and demonstrates how differences are malleable and perceived as sources of equilibrium and renewal. (Bennett, 1993, p. 1) (See figure 6. 1).

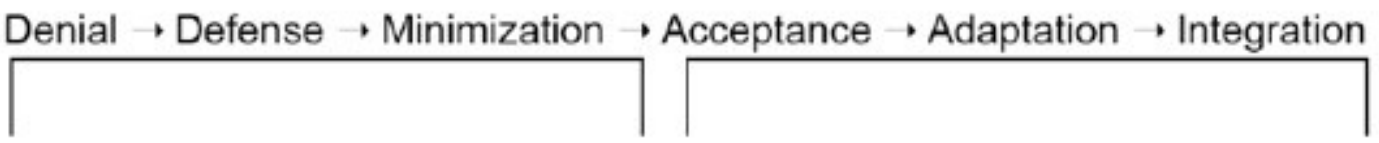

ETHNOCENTRISM

\section{ETHNORELATIVISM}

\section{Figure 1: The developmental model of intercultural sensitivity. [Source: Bennett, 2004.]}

The basic explanation given to these stages is that the first phase includes terminologies as denial meaning there is no difference, defense or against the difference and minimization of the difference making this phase more 
ethnocentric. However, the second phase that includes acceptance of a new way of seeing, adaptation of a new way of acting and integration to a new way of being are more ethno-relativist. (Bennett,1993).

\section{Education Cooperation Benefits to Cameroon \\ 3.1 Quality Assurance in Education}

Learning and training quality are sensitive areas of action in any education system. Vegas \& Petrow, (2007), writing about education quality in developing countries, argue that expansion of educational opportunities has not markedly reduced poverty, income inequality, and underdevelopment possibly due to the poor quality of education. This depicts the situation in Cameroon where the poor-quality learning and training is prevalent with poorly designed curriculum not well oriented towards practical needs of the society. Key factors contributing to poorquality learning and training include teachers with inadequate qualification. Lack of qualified teachers is also due to limited number of professionals and lack of direct contact of teaching staff with industries and job market, particularly for the case of Technical and vocational education, which does not enable those teachers to update their knowledge with the transforming market for providing teaching relevant to the employment market (Mvuh, 2017). Moreover, the lack of professionals can also be related to the limited linkage between Cameroonian higher education institutions and foreign institutions to enable teachers gain more experiences and potentially learn good practices from outside.

Furthermore, adequate teaching manuals, sufficient training document, well-developed training curriculum are missing to deliver quality education in Cameroon. The curriculum is still basically theoretical, lacking real contact with the Cameroonian society and her needs. In 2007, the Ministry of Secondary Education (MINESEC), the Ministry of Tertiary Education (MINESUP), in conjunction with the Ministry of Employment and Vocational Training (MINEFOP) implemented a project of curriculum development putting emphasis on the skill-based approach. However, by 2012 only 15 training course programme has been developed according to the Skills-Based Approach and approved (Kom, 2012), demonstrating the inadequacy of learning programme and professionals that could provide input for the efficient curriculum development, which will increase productivity, creativity, adaptability, and employability among the youth.

Moreover, in well-functioning education system, financial transfers, political interventions, rules and regulations concerning performances and outcomes are clearly set up and implemented to ensure a quality of administration management (World Bank, 2015). Nevertheless, the management of the education in Cameroun is dominated by a lack of transparency in finance, teacher recruitment, and political interference. According to the Transparency International (2016), Cameroun has been identified as having one of the highest reports of "petty misuse of funds" and the country is ranked 145/176 on the developing countries corruption index. Financial transfer from the central administration to the regions and sub-divisions are low and inadequately managed. The funds provider (the central government to regional, then regional to educational institutions) makes transfers without any clear system of reporting or accounting. Mismanagement in Cameroun's education sector reflects in resources wastages as school sites are selected without recourse to the country's needs. The wasting of resources in turn contributes to reduced investment in schools and classrooms equipment, offices and, insufficiency in teaching and learning infrastructures.

In addition, the growing number of learners in Cameroon, due to the rapid development of the population with youths representing over 60\% (National Institute of Statistics, 2013), has called for more investment in the education sector to respond to the teaching and learning needs. However, because of the economic limitations in the country, education is faced with shortage of basic infrastructure which impact hugely the education provision. It has been observed that $57.2 \%$ of technical schools do not have any workshop; many tertiary colleges do not have functional laboratories; learning and teaching materials are old and $4.4 \%$ of schools are made up with makeshift materials. The existing infrastructure are inadequate and nonspecialized, with insufficient maintenance. At the time of Information and Communication Technologies, $24 \%$ of secondary institutions do not possess functioning computers available for students (National Institute of Statistics; 2010). The problem of lack of infrastructure inhibits the opportunities to receive good practice and acquire the necessary skills for their development. Many of the students interviewed at the Douala Institute of Technology, who were on internship in a Chinese company in Yaoundé during the course of the research complained about the inability for them to have enough practical experience due to lack of infrastructure in their institution,

Being aware of the above problems negatively infecting the education quality, Cameroon took commitment to intensify her international cooperation in education with hope to come up with solutions. In her cooperation agenda, China has been taking a priority place with respect to the China's booming economy. Indeed, ChinaCameroon education cooperation has resulted many benefits in terms of education infrastructure provision, job opportunities, education management, etc.

At the infrastructural level, the education cooperation between China and Cameroon has enabled the construction of primary schools and secondary technical and vocational school in Cameroon, and the Confucius Institute at the University of Yaounde II; the construction of microbiology laboratory within the University of 
Yaounde I. Cameroon has received many learning and teaching materials from China including books, computers etc which have been useful in enhancing the schools' environment thereby attracting more students to be enrolled. The microbiology laboratory for example has enabled to deliver high-quality training to master and doctoral students. Indeed, it has allowed to collaborate with the Chinese researchers for multi-dimensional researches and practices in fermentation. For instance, one of the biggest projects which have come to supply the gap in manufacturing and researching in Cameroon through the microbiology lab has been the project of "Tapioca's alcoholic fermentation". This is a significant project because the basic materials used can be found locally and is economically beneficial for Cameroonians.

At the management level, China-Cameroon education cooperation has provided training opportunities in China for Cameroonian education managers through the inter-university partnership, the education delegations from Cameroon have participated in several seminars in China. From 2002 to 2006, Cameroonians education delegations participated in about 40 seminars in China through the partnership between the University of Yaounde I and Zhejiang Normal University (Shengyu, 2017). Other seminars such as Short-term training for Cameroonian teachers in the high schools holds every summer in Zhejiang Normal University. These trainings in China have been expanding horizons for research, thus creating new visions and enhancing quality and innovation to the improvement of the education system in Cameroon. The international experiences gained by the trainees create and develop broader network of contacts in education and professional fields. In terms of teaching, the Cameroonians education managers are benefiting from experience in curriculum development as well as degrees obtained from collaborations with partnering higher education institutions. For instance, Cameroonian undergraduates with major in the Chinese language at the Teachers' Training College of the University of Maroua can enter Chinese universities for a master program in teaching Chinese as a result of the mutual recognition of degrees. In terms of management, the trainees are benefiting in the area of knowledge and experiences related to management and finance thereby enhancing their capacity in handling management financing problems. During a seminar on schools' management and reinforcement of capacities in African Francophone Countries organized in May 2018 by Zhejiang Normal University/ College of International Education, a professor of the University of Yaounde I submitted: "China has a great experience in school management, this might be the reason why their education has developed so fast. I intend to recommend to my institution these strategies here and I strongly hope it can be adapted and help my home country solve her management problems."

Other benefits for Cameroon related to international education cooperation with China is the training of Cameroonian students through the provision of scholarships including the bilateral scholarship, the Confucius Institute (CI) scholarship and the inter-university scholarship. According to some sources about 40 scholarships in total are offered to Cameroonian students each year (AFRODAD, 2011). The benefits of these scholarships include the opportunity to study high-quality programs with relatively abundant learning resources; the development of intercultural perception and a providing recipients with opportunity to experience benefits of internationalization; the development of multilingualism; the stimulation of open-mindedness; the personal growth, etc. To this effect, Guy Birkin, Tristram Hughes \& John Brennan (2014) argued that, international cooperation in education enable the cultivation of positive attitudes regarding diversity in society, reduce prejudices, respect the rights of others, improve engagement in learning and challenging to be more creative. Hayden, Mary; McIntosh, Shona (2018a) added that it contributes to development of communication and interpersonal skills, foreign language acquisition, self-directed learning which have value in a broad range of jobs.

\subsection{Employment Opportunities for Cameroonians}

Economically, Cameroon is confronted by a high unemployment rate among youths which represent more than 60 percent of the total population; and low productivity due to the inadequacy of training and low quality in education provision. The country's GDP Annual Growth Rate averaged 4.64 percent from 2003 until 2016, which is relatively low compared to other Sub Saharan countries (World Bank, 2017). Cameroon has been trying to offer employment opportunities to her young people through the educational cooperation with China. The growing interest of Cameroonians to learn Chinese language has resulted in many employment opportunities. In fact, this study conducted a survey related to the employment status of Cameroonian Chinese learners. The results show that some of the students at the CI within the University of Yaounde II had working experience with Chinese enterprises established in the country. For those who have just began to learn the Chinese language, they hope to find a job as translator in a Chinese company in the future. Although the level of satisfaction in term of language acquisition has been relatively low compared to students coming from China, but these job opportunities have been filling the gap of unemployment among Cameroonian youths.

For those students who have studied in China, they easily find good jobs with high salaries due to their international experiences. Indeed, international experiences in China prepared and endowed the students with new knowledge and expertise to confront the world of work and be more competitive. Some Chinese employers from CRRC (China Railway in Cameroon/中国中车) or from some Chinese car workshops rated Cameroonians with international experience by far superior to those with none in terms of competence. The competences identified by 
these Chinese employers were the well-acquisition of the Chinese language and culture, better written skills, greater adaptability and assertiveness. This confirm the fact that international experience can add more value to the future career of a student. This tallies with Guy Birkin, Tristram Hughes \& John Brennan (2014) that, students who have international experience demonstrate deeper experience and provide a more rounded set of abilities. According to these authors, foreign language skills, communication and interpersonal skills are increasingly valued by employers. Beside the Chinese, Cameroonian employers have also been very impressed of candidates having international experiences.

\section{Benefits of the Education Cooperation to China}

Writing on the advantages of the international education cooperation between China and her foreign partners, Guimin Feng argued that, China is benefiting in terms of developing her education sector, increasing international trade in China, attracting foreign investment, and attracting high-quality resources (Guimin, 2016). Guimin's argument seems to be very relevant when looking at China's cooperation with developed countries. However, it would be hard to accord the same argument when it comes to poor developing countries in Africa. Some authors argue that the main benefits of China in her cooperation with poor African nations include the expansion of China's soft power (King, 2014); the internationalization of China's higher education institutions and the provision of research and job opportunities to the Chinese youths through volunteering.

\subsection{Internationalization of China's Universities}

Internationalization is a multidimensional and complex concept that has been defined in different contexts. King (1994) defined internationalization of higher education as a "process of integrating an international dimension into learning/teaching, research and the service function of university". According to DONCHENKO (2015), internationalization of higher education seeks to facilitate institutional development, improve the quality of education, create opportunities for exchanging resources, and foster research and innovation (DONCHENKO, 2015). The internationalization of higher education is viewed as a way nations respond to the influence of globalization (Knight, 1999; Huang, 2002). Talking of globalization, the IMF (2000) noted that, it is the development of growing integrated economic, political, technological, relationship and cultural systems that transcend the national boundaries and operate in real time. In today's increasingly global, complex and competitive world, the internationalization of higher education has become a strategic priority for higher education institutions and governments as well to face the challenges of modern world. To this effect, ELAINE MARCIA HAYLE (2008) argued that, global forces and processes have pushed higher education institutions and governments to examine critically their operations and have presented opportunities to share ideas amongst institutions over the world (Hayle, 2008). The common elements or components of internationalization that have been identified by scholars include the recruitment of international students, the international exchange of scholars or students, curriculum innovation, foreign language study, and international co-curricular activities (Knight, 1994; Cudmore, 2005; de Wit, 2002).

The benefits of China's higher education internationalization are consistent with the advantages or benefits of higher education internationalization in general. These benefits can be organized in different levels including the government level, the institutional and the student level.

The governmental benefits of internationalization include the Chinese engagement to be effectively part of "global village". Thus, the Chinese government strongly supports and encourages its higher education institutions to establish linkage with foreign institutions including African universities. typical example has been the recent approval by the Chinese government tof the education cooperation and exchanges between the Zhejiang Normal University and the University of Yaoundé I in the cadre of 20+20 plan. Guimin Feng (2016) argued that, Sinoforeign international cooperation in education helps to promote its competitive power in severe and intense market competition to strongly activate the Chinese education market. This is to say, through the internationalization of her universities, China will benefit from the expansion of her education in Cameroon and that will not only help to increase the China's good reputation, but also to attract more students and develop China's investments.

Besides, with the presence of many international students including Africans and particularly Cameroonian students within the Chinese university campuses, the intercultural communication skills are better developed and, learning and teaching experiences come to be more enriched (Mestenhauser, 2002; Paige, 2003). Indeed, their interactions with domestic peers has been associated with social and academic benefits. In one hand the presence and interaction with international African students including Cameroonians allow the acceptance of social diversity, increase cultural awareness among Chinese students, helps reduce prejudices towards others and foster intercultural friendships; in the other hand, it brings about international perspective into classroom discussions, challenging and encouraging teachers to consider new practices consistent with the students' different experiences. Furthermore, the testimony of many international students from Africa and Cameroon particularly reveals that the presence of more international students within the campus of Zhejiang Normal University has had positive impact on the Chinese local community (Jinhua city) in terms of cultural awareness, and acceptance of diversity in the 
world.

The institutional benefits of the Chinese higher education internationalization aligned with the research opportunities abroad, enhancement of quality education and economic benefits. For instance, the educational cooperation between Zhejiang Normal University and universities in Cameroon enabled scholars and researchers from the Institute of African Studies/Zhejiang Normal University to conduct researches in Cameroon; it enable Cameroonians and Chinese educational experts to share ideas and education experiences through seminars; it also helped Chinese universities to attract more self-funded students from Cameroon which contribute in generating income for these universities.

\subsection{Improvement of China's Soft Power in Africa/Cameroon}

In today's society, the struggle for international influence has not only been fought through military forces or economic instruments, rather, it has been easier to win people's hearts and confidents around the world by attraction than intimidation. The term characterizing such phenomenon in literature has been called "Soft Power". The later expression was introduced by the American Joseph NYE in the 1990s who thought that a nation can acquire "Soft Power" through three different ways including its political values, foreign policy and its culture. However, NYE underlined that these values cannot be established artificially as their fundamental existence will shape the attraction (NYE, 2004). It has been noted an increased use of soft power in China since the President Hu Jintao alluded to the "great rejuvenation of the Chinese nation by the thriving of Chinese culture" in 2007 during the 17th National Congress of the CPC (Communist Party of China). President Hu's initiative was renewed in 2014 by his successor Xi Jinping who reiterated the willingness to improve the China's soft power, giving a good Chinese narrative and well communicate the China's values to the world. In 2017 at the 19th CPC's Congress, Xi employed the term of "soft power with Chinese characteristics", showing the country's increasing ability to advance strategic interests through cooperation and inducement. The characteristics of China's soft power are based on the principles of mutual benefits and common development. Thus, the Chinese soft power engagement in developing countries and Africa particularly includes:

$>\quad$ The promotion of solidarity with Africa on trade and human rights issues at international scene;

$>\quad$ The reduction of African countries debts;

$>\quad$ Development mode and economic attractiveness;

$>\quad$ Foreign policy and activities;

$>\quad$ National image;

Assistance and provision of public goods;

$>\quad$ The increasing investment in energy as in infrastructural and agricultural areas (Yumei, 2007).

In the education field particularly, major tools of China's soft power in Africa include:

$>\quad$ The provision of more scholarships for students and more training opportunities for officials and military corps;

$>\quad$ The dispatch of volunteers in Africa;

$>\quad$ The establishment of CIs.

Indeed, in terms of scholarship provision, it is important to note here that the number of students in China on scholarship has grown from 2000 in 2003 to nearly 50,000 in 2015 (Victoria Breeze \& Nathan Moore, 2017). These scholarships are not been only focusing on language training, they have extended to include areas such as science and technology, engineering, information and communication, finance agriculture, medicine etc. The benefits of these scholarships are expressed in the experience these students get in China and which translate into their willingness to work with Chinese and view China's external as well as internal policies favorable for their future.

In terms of training, China launched the African Talents Program in 2012, aiming to train about 30,000 African professionals between 2013 and 2015 and accelerate the technology development in African nations. China also increased the number of scholarships for training African government leaders from 200 to 1000 in 2016 and training have been hosted by the CPC Central Party School. The content of the training has been covering leadership training, governance, parliaments, management and African participant have been taking field trips to deepen knowledge on how Cadres from political party solve local problems. Apart from these trainings, China also took commitment to create agricultural training centers in African countries.

China has already established over 70 Confucius Institutes (CIs) and Confucius classrooms in Africa (China Daily, August 8, 2018). These institutions have been providing teaching of Chinese language and promoting the Chinese culture. With respect to this mission of the CIs, many scholars view their establishment as a powerful tool of China's soft power in developing countries (Procopio, 2015; R.S. Zaharna, Jennifer Hubbert, 2014). A Cameroonian scholar, Momo Ngomba (2017) demonstrated how the establishment of the CI in Cameroon have come to influence Cameroonians minds about China and her people. Nevertheless, contrary to these considerations, the Director of the Headquarter of the CI in Beijing, Madame Xu Lin refuted the fact that the establishment of CIs is part of China's soft power in Africa (King, 2014). According to her, the CIs aim to show to the world the Chinese 
culture and its values, they intend to present the real China, not the one erroneously described in foreign literature and help to increase understandings between China and the outside world. With respect to the explanation given by Madame $\mathrm{Xu}$, some studies reveal that this strategy is considered as a soften process of improving the Chinese reputation abroad and specially in Africa, it is argued this strategy has been helping to maintain positive attitudes of Africans young generations towards China (Paul Nantulya, 2018).

Other educational programs mentioned to be part of the Chinese soft power involve the establishment of China Africa Think Tank forum. Financed by the China Development Bank, China-Africa Think Tank Forum was established in 2011, aiming to promote joint policy research and training between top African and Chinese private government think tanks. The research and training programs have been involving the trade relations, security cooperation, governance and United Nation Reform. For instance, in July 2018, China held the seventh Think Thank Forum in Beijing gathering over 380 senior researchers and leaders from Africa and China, and where major points of the agenda were to discuss about the One Belt One Road Initiative and several other policy prescriptions about industrial cooperation, aid, and trade, and that resolutions have been adopted during the FOCAC 2018 Summit. Some authors argued that such partnership has been part of China's efforts to broadly generate African support for the Chinese policy positions.

Overall, the education program of the partnership between China and Africa is likely to boost the China's soft power and her popularity in Africa. Through the cultural interactions, Cameroonian youths particularly are increasingly fascinated by the Chinese culture and values (movies, music, cuisine, arts, herbal medicine etc.), and academic exchanges have also been helping to improve African leaders' vison towards China. The improvement of their vision is also due to the fact that China's soft power is based on the principles of mutual benefits and common development. Many Chinese scholars estimate that China has been using soft power in Africa to improve friendship and understanding. Therefore, in her struggle to win African people hearts, China never imposed her ideology nor morality; the political system that has been guiding assistance's provision to Africa never carried any political conditions. China's soft power is performed in smooth and silent way. These are the reasons why China's aid seems to be more attractive, leading Africans sentiment towards China being largely favorable, despite the fact that China is still lagging behind the United States in terms of soft power in the continent according to some sources (Economist/Burundi, August 21st, 2014).

\subsection{Job and Research Opportunities for Chinese Young People}

As a result of the various education exchanges between China and Cameroon, Chinese students have been benefiting from some job and research opportunities in Cameroon through the Chinese volunteering program. The work of volunteers has been proved scientifically to provide many benefits. These benefits include a better physical and mental health that address social problems and building up social cohesion (Wilson, 2000). Volunteering provides best opportunities to develop personal skills. In the field of education, Chinese volunteers going to Cameroon generally are sent to work at the Confucius Institute at the University of Yaounde II as Chinese teachers. Most of these students are graduate or master students who have been conducting some research concerning Africa or who have been studying Chinese language teaching to foreigners. Thus, the work of volunteering has been providing to them an indicated environment for their research, and also it has been enabling to develop their personal values; the interactions with Cameroonian peers has also been helping Chinese volunteers to increase their cultural awareness; finally, it has been offering to them psychological and economic benefits.

\section{Principal and Common Benefit to China and Cameroon: Reinforcement of Diplomatic Ties}

According to Stephen McGlinchey (2017), diplomacy is fundamental tool to successfully operate in today's international system. Cameroon and China have experienced 48 years of diplomatic relations till date, enriched with various exchanges in political, social, economic and cultural fields. In social domain for example, the education cooperation has played a major role in enhancing mutual understanding and strengthening diplomatic friendships. Nevertheless, the educational cooperation has helped at improving diplomatic relations between Cameroon and China in many ways.

With the establishment of the Confucius Institute within the university of Yaoundé II in 2007; and the commencement of the only Chinese major in the whole Central Africa within the University of Maroua in the FarNorth region of Cameroon 2008; the inclusion of the Chinese language as optional course in public secondary schools since 2010, many Cameroonians have learned enough knowledge about China and Chinese culture. At the same time, many universities in China have created multiple centers for African studies, enabling the Chinese people to be more informed about African culture and social values through scientific research and cooperation with universities in Africa including Cameroon. Studies have shown that criticisms and prejudices towards a country or people often happen when we are ignorant of their realities; knowledge of other country positively impacts our behavior and help to reduce prejudice toward others (Cambridge, James; Thompson, 2004). Thus, the educational cooperation between China and Cameroon has been beneficial in terms of increasing mutual 
understanding among their peoples; it has allowed them to go beyond the histories related to them by third party sources and helped to rebuild their new and real images trough scientific research and cooperation. As far as mutual understanding and mutual confidence are concerned, the Cameroonian government has been committed to accord most of her developmental projects to China. According to some sources, $70 \%$ of big projects in Cameroon are accorded to the Chinese entrepreneurs (Khan \& Baye, 2008). This mark of confidence, essential tool in diplomatic exchanges, has been beneficial both for Chinese to expand their market in Cameroon and for Cameroonians to realize their developmental projects and deepen relationship with an economically advanced country such as China. This corresponds to the idea of McGlinchey (2017) who defines diplomacy as a process amongst international actors engaged in public or private dialogue (diplomacy) to pursue their goals in a peaceful manner.

Beside the institutions such as the CI in Cameroon and the African research centers in China such as the Institute of African Studies within The Zhejiang Normal University, another component of education cooperation that has been helping to strengthen diplomatic friendship between China and Cameroon has been the provision of scholarships to Cameroonian students and the work of Chinese volunteers in Cameroon. Thanks to scholarship provision, Cameroonians students can become "ambassadors" of China in their home country. In other words, the time spent in China allows to well understand the culture and society, and therefore be able to defend the Chinese image and promote their societal value within the Cameroonian society. At the same time the work of volunteers also helps to experience Cameroonians mode of life, learning and understanding their culture, and therefore can act as Cameroonian "ambassadors" in China, thereby promoting mutual understanding and strengthening the diplomatic relationship.

\section{Conclusion}

Theoretically, there are evident benefits of international education cooperation on individual, education institutions and the government development. However, for the case of educational cooperation between China and Cameroon particularly, there is lack of publicly available information about the benefits resulted to the said cooperation. Nevertheless, our research findings show that, China-Cameroon education cooperation has contributed to improve the quality of education in Cameroon through the provision of education infrastructures, with the participation of various educational seminars and short-term training in China among others. Furthermore, Cameroonians have benefited from some employment opportunities thanks to the establishment of Confucius Institute within the University of Yaounde II, and thanks to the Chinese scholarships which have helped in boosting students' employability. In the same perspective, China has benefitted in the bolstering of her university internationalization, the expansion of her soft power in Cameroon and has been increasing job and research opportunities for young Chinese volunteers in Cameroon. Finally, the principal and common benefit shared by both China and Cameroon relies on the improvement of the two partners diplomatic ties. As a result of education cooperation, both countries have deepened mutual understandings, friendship and solidarity.

\section{References}

Baoping, L. (2006). On the Issues Concerned with China-Africa Education Cooperation, (May), 1-13.

British Council. (2014). Research and Analysis of the Benefits of International Education Opportunities, A literature review on opportunities for international experience in the UK, and comparison with the US and Germany.

Cambridge, James; Thompson, J. (2004). (2004). Internationalism and globalization as contexts for international education. A Journal of Comparative and International Education, 161-175.

China Daily. (2018). No Title.

Economist/Burundi. (2014). Pew Research Global Attitudes Project.

Hayden, Mary; McIntosh, S. (2018a). International education: the transformative potential of experiential learning. Oxford Review of Education, 403-413.

Hayden, Mary; McIntosh, S. (2018b). No Title.

Juliana, M. N. (2017). How China's Confucius Centers affects Cameroon's Culture.

King, K. (2014). China's Aid \& Soft Power in Africa: the Case of Education and Training. Zhejiang University Press.

Lucker, G. W., Rosenfield, D., Sikes, J., \& Aronson, E. (1976). Performance in the interdependent classroom: A field study. American Educational Research Journal, 13, 115-123.

McCollow, J. (1989a). No Title.

McCollow, J. (1989b). Secondary education as an international commodity, The Australian Teacher, 23, 10-13.

McGrath, Simon; Gu, Q. (2015). Routledge Handbook of International Education and Development. Oxon: Routledge, P.133.

Mvuh, Z. and colleagues. (2017). China Enhancing Education Development in Africa : A Case Study of Cameroon, $7(15), 18-19$.

Nordtveit, B. H. (2011). An emerging donor in education and development: A case study of China in Cameroon. 


International Journal of Educational Development, $\quad 31(2), \quad 99-108$.
https://doi.org/10.1016/j.ijedudev.2010.01.004

NYE, J. S. (2004). Soft Power: The Means To Success In World Politics.

Ping, Q. (2013). Educational exchanges and cooperation in the Central African historical process research and development(1949-2006).

Procopio, M. (2015). The effectiveness of Confucius Institutes as a tool of China's soft power in South Africa. Centre for Chinese Studies, Stellenbosch University.

R.S. Zaharna, Jennifer Hubbert, and F. H. (2014). Confucius Institutes And The Globalization Of China'S Soft Power.

Tate, N. (2013). International education in a post-Enlightenment world. Educational Review, 253-266.

Wessala, G. (2011). Enhancing Asia-Europe Co-operation Through Educational Exchange. Oxon: Routledge, P.73.

Wiegel, R. H., Wiser, P. L. , \& Cook, S. W. (1975). The impact of cooperative learning experiences on crossethnic relations and attitudes. Journal of Social Issues, 31, 219-244.

Wiseman, A. (2018). Annual Review of Comparative and International Education 2017. WA: Emerald Group Publishing, 211-212.

World Bank. (2017). Cameroon, GhanalData. Retrieved from https://data.worldbank.org/?locations=CM-GH

Yumei, L. (2007). China's Soft Power and the Development of China-Africa Relations. CHINA INTERNATIONAL STUDIES.

牛长松. (2010). 中国与非洲教育合作的新范式. C o m p a r a t i v e E d u c a t i o n R e v i e w, $N o .4$.

贺文萍. (2007). 中非教育交流与合作概述一一发展阶段及未来挑战, 第3 期. 